\title{
Effects of (complementary) Polyelectrolytes Characteristics on Composite Calcium Carbonate Microparticles Properties
}

\author{
CRISTIAN BARBU MIC ${ }^{1,2}$, MARCELA MIHAI ${ }^{1}$, CRISTIAN DRAGOS VARGANICI ${ }^{1}$, SIMONA SCHWARZ ${ }^{3}$, DAN SCUTARU', \\ BOGDAN C. SIMIONESCU1* \\ 1Petru Poni Institute of Macromolecular Chemistry of Romanian Academy, 41 A Grigore Ghica Voda Alley, 700487 Iasi, Romania \\ ${ }^{2}$ Gheorghe Asachi Technical University of lasi,Department of Natural and Synthetic Polymers, 73 Prof. Dimitrie Mangeron Str., \\ 700050 lasi, Romania \\ ${ }^{3}$ Leibniz Institute of Polymer Research, 6 Hohe Strasse, 01069 Dresden, Germany
}

\begin{abstract}
This study follows the possibility to tune the thermal stability of some $\mathrm{CaCO}_{3} /$ polymer composites bycrystal growth from supersaturated solutions controlled by polymer structure or by using nonstoichiometric polyelectrolyte complexes (NPECs). As the ratio between the organic and inorganic parts in the composites controls the $\mathrm{Ca}^{2+}$ /polymer network crosslinking density, the $\mathrm{CaCO}$.jpolymer weight ratio was kept constant at 50/1, varying the initial concentration of the polyanions solutions ( 0.05 or 0.06 wt.\%), the NPECs molar ratio,$n+/ n^{-}(0.2$ or 0.4$)$, or the inorganic precursors concentration $(0.25$ or $0.3 \mathrm{M})$. Poly(2-acrylamido-2methylpropanesulfonic acid-co-acrylic acid) (PSA) and chondroitin-4-sulfate (CSA) were used as polyanions. Some NPEC dispersions, prepared with the same polyanions and poly(allylamine hydrochloride) (PAH), were also used for calcium carbonate crystallization. The characteristics of the prepared composites were investigated by scanning electron microscopy (SEM), flow particle image analysis (FPIA), particles charge density $(C D)$, zeta-potential (ZP). The thermal stability of the composite particles was investigated as compared to bare $\mathrm{CaCO}_{3}$ microparticles prepared at the same initial inorganic concentrations.
\end{abstract}

Keywords: $\mathrm{CaCO}_{3}$ /polymer composites, polyanions, polyelectrolyte complexes, thermal stability

Calcium carbonate is one of the most abundant materials on the planet and has been used for various polymer composites. $\mathrm{CaCO}_{3}$ exists in three types of crystalline form: calcite, the moststable form with trigonalrhombohedral structure, aragonite, of orthorhombic crystal structure, and vaterite, which exists in hexagonal form. The properties and applications of $\mathrm{CaCO}_{3}$ depend on the morphology, polymorphism, particle size, and chemical purity of the crystals. A well-known application of $\mathrm{CaCO}_{3}$ is its use as filler for plastics, aiming to improve some product properties - physical, rheological, thermal and mechanical. $\mathrm{CaCO}_{3}$ has received an increased attention due to its wide range of potential applications and its low cost $[1,2]$. Thermal stability is the key factor used to evaluate the application area of materials and thus the thermal stability of polymers and composites need to be investigated to meet application requirements.

Many studies showed a correlation between calcium carbonate growth characteristics and the structure of the additive organic molecules [3-7]. However, difficulties in understanding their respective roles arise from the complexity in studying such mechanisms in the solid-liquid systems and the large ability of the $\mathrm{CO}_{3}{ }^{2-}$ anions to form different supramolecular structures.

Numerous studies have been carried out to understand the influence of organic molecules on $\mathrm{CaCO}_{3}$ particle growth, and various additives including surfactants [8], macromolecules [9-14], amino acids [15], extracts $[16,17]$, ionic liquids [18], etc., have been investigated. Recent studies discuss the use of nonstoichiometric polyelectrolyte complexes (NPEC) as templates in controlling $\mathrm{CaCO}_{3}$ crystals growth $[19,20]$. The NPEC dispersion characteristics, such as molar ratio, particles size and charge density slightly affect the $\mathrm{CaCO}_{3} / \mathrm{NPEC}$ composite particles surface morphology, electrokinetic parameters and the polymorphic content. $\mathrm{CaCO}_{3} / \mathrm{NPECS}$ composite microparticles also show increased microparticles resistance againstEDTA as chelating agent, the arrangement of preformed NPECs into the composites and the $\mathrm{Ca}^{2+}$ ions bridges formed between shorter anionic chains remained uncompensated by the cationic polymer probably conducting to a dense netw ork matrix [20].

In this context, the aim of this study was to investigate the possibility to tune the thermal stability of some $\mathrm{CaCO}_{3}$ polymer composites by crystal growth from supersaturated solutions controlled by polymer structure or by using NPECs. As the ratio between the organic and inorganic parts in the composites controls the $\mathrm{Ca}^{2+} /$ polymer network crosslinking density, in this study the $\mathrm{CaCO}_{3} /$ polymer weight ratio was kept constant at 50/1, varying the initial concentration of polyanions solutions $(0.05$ or 0.06 wt. $\%)$, the molar ratio of NPECs , $n^{+} / n^{-}(0.2$ or 0.4$)$, or inorganic precursors concentration $(0.25$ or $0.3 \mathrm{M})$. Two polyanions were used: poly(2-acrylamido-2-methylpropanesulfonic acid-co-acrylic acid) (PSA) which is a synthetic, flexible polymer, and chondroitin-4-sulfate (CSA), a sulphated glycosaminoglycan with a semi-rigid macromolecular chain. Some NPEC dispersions, prepared with the same polyanions and poly(allylamine hydrochloride) (PAH) as polycation, were also used for calcium carbonate crystallization. Scanning electron microscopy (SEM) was used to provide particles morphology, and flow particle image analysis (FPIA) to evidence their mean size and circularity. Polymer presence into the composite particles was evidenced by particles charge density (CD) and zeta-potential (ZP). The thermal stability of the composite particles was investigated as compared to bare $\mathrm{CaCO}_{3}$ microparticles prepared at the same initial inorganic concentrations.

\footnotetext{
* email: bcsimion@icmpp.ro; Phone: +40.232217454
} 


\begin{tabular}{|c|c|c|c|c|c|}
\hline Sample code & $\begin{array}{l}\left.\mathrm{Na}_{2} \mathrm{CO}_{3}\right]= \\
{\left[\mathrm{CaCl}_{2}\right], \mathrm{M}}\end{array}$ & $\begin{array}{l}\mathrm{CaCO}_{3}, \mathrm{~g} / 100 \\
\mathrm{~mL}\end{array}$ & $\begin{array}{l}\text { Polymer, } \\
\text { wt. \% }\end{array}$ & $\begin{array}{l}\text { Polymer, } \\
\mathrm{g} / 100 \mathrm{~mL}\end{array}$ & $\mathrm{CaCO}_{3} /$ Polymer, g/g \\
\hline $\mathrm{C}_{0.25}$ & 0.25 & 2.5 & - & - & - \\
\hline $\mathrm{C}_{0.25} / \mathrm{PSA}_{0.05}$ & 0.25 & 2.5 & 0.05 & 0.05 & $50 / 1$ \\
\hline $\mathrm{C}_{0.25} / \mathrm{CSA}_{0.05}$ & 0.25 & 2.5 & 0.05 & 0.05 & $50 / 1$ \\
\hline $\mathrm{C}_{0.3}$ & 0.3 & 3 & - & - & - \\
\hline $\mathrm{C}_{0.3} / \mathrm{PSA}_{0.06}$ & 0.3 & 3 & 0.06 & 0.06 & 50 \\
\hline $\mathrm{C}_{0.3} / \mathrm{CSA}_{0.06}$ & 0.3 & 3 & 0.06 & 0.06 & 50 \\
\hline & & & $\mathrm{n}^{+} / \mathrm{n}^{-}$ & & \\
\hline $\mathrm{C}_{0.25}$ (PSAPAH) 0.2 & 0.25 & 2.5 & 0.2 & 0.0484 & $51.65 / 1$ \\
\hline $\mathrm{C}_{0.25} /(\mathrm{PSA} / \mathrm{PAH})_{0.4}$ & 0.25 & 2.5 & 0.4 & 0.0493 & $50.71 / 1$ \\
\hline $\mathrm{C}_{0.25} /(\mathrm{CSA} / \mathrm{PAH})_{0.2}$ & 0.25 & 2.5 & 0.2 & 0.0472 & $52.97 / 1$ \\
\hline $\mathrm{C}_{0.25} /(\mathrm{CSA} / \mathrm{PAH}) 0.4$ & 0.25 & 2.5 & 0.4 & 0.0482 & $51.87 / 1$ \\
\hline
\end{tabular}

Table 1

$\mathrm{CACO}_{3} /$ POLYANION

COMPOSITES

PREPARATION

CONDITIONS

\section{Experimental part \\ Materials}

$\mathrm{CaCl} \cdot 2 \mathrm{H}_{2} \mathrm{O}$ and $\mathrm{Na}_{2} \mathrm{CO}_{3}$ from Sigma-Aldrich were used as received. The PSA copolymer, which contains 55 mol.$\% 2$-acrylamido-2-methylpropanesulfonic acid and $45 \mathrm{~mol}$ $\%$ acrylic acid, was synthesized and purified according to ref. [21]. CSA from bovine trachea was purchased from Sigma and used as received. PAH of low molar mass from Fluka was used without further purification.

\section{Preparation of $\mathrm{CaCO}$.polymer composites}

The formation of $\mathrm{CaCO}_{3} /$ polyanion composites was carried out in glass beakers, at $25^{\circ} \mathrm{C}$, according to the procedure already published [19]. The $\mathrm{CaCO}_{3} /$ polymer weight ratio was close to 50/1 for all samples, as shown in table 1.

For NPEC preparation, the concentration of polyanions aqueous solution was $1.7 \times 10^{-3}$ and $10^{-3} \mathrm{M}$ for PSA and CSA, respectively, whereas $\mathrm{PAH}$ aqueous solutions concentration was $5 \times 10^{-3} \mathrm{M}$. Dispersions of NPEC were prepared by mixing the solutions of oppositely charged polyelectrolytes in appropriate proportions, according to the desired mixing molar ratio, $\mathrm{n}^{+} / \mathrm{n}^{-}(0.2$ or 0.4$)$. After mixing, the formed dispersions were stirred $60 \mathrm{~min}$ and were characterized and used in composite preparation after $24 \mathrm{~h}$.

The composites were prepared by solving $\mathrm{Na}_{2} \mathrm{CO}_{3}$ in the polyanion aqueous solution or in the NPEC dispersion. Equal volumes of as prepared solutions or dispersions were rapidly mixed with a $\mathrm{CaCl}$, aqueous solution, with $\mathrm{Na}_{2} \mathrm{CO}_{3}$ and $\mathrm{CaCl}_{2}$ having equal concentrations. The mixtures were stirred for 1 min on a magnetic stirrer and then kept under static conditions for $30 \mathrm{~min}$. The obtained microparticles were separated by filtration, intensively washed with water and finally washed with acetone and dried in oven at $40^{\circ} \mathrm{C}$, for $1.5 \mathrm{~h}$. Samples with the same inorganic concentration and without polymer were prepared for comparison purposes.

\section{Characterization of composite microparticles}

The particles shape and surface were examined by using a FEl Phenom Desktop Scanning Electron Microscope, in high vacuum mode. To avoid electrostatic charging the particles were sputtered with gold.
The particles size distribution of the carbonate particles was evaluated using the Sysmex Dynamic Flow Particle Image Analyzer 2100. To obtain correct values, the Sysmex FPIA 2100 image analyser was checked before starting the main experiment by using certified size standards.

The electrokinetic potential of carbonate samples was measured by means of ZetaSizer Nano ZS (Malvern, UK) operating at the $633 \mathrm{~nm}$ wavelength. The instrument measured the electrophoretic mobility of the particles. From the electrophoretic mobility the apparent zeta-potential values $\left(\zeta_{\text {app }}\right)$ were calculated by the Smoluchowski's equation. The presented values are average values of at least three independentmeasurements performed for each sample on $0.5 \mathrm{mg} / \mathrm{mL}$ aqueous dispersions.

The concentrations of the charged groups in microparticles dispersion were determined by titration using the Mütek PCD 03 (BTG Instruments GmbH, Herrsching, Germany) particle charge detector. The charge density was calculated from the amount of standard solutions [ poly(sodium ethylenesulfonate) or poly (diallyldimethyl ammoniumchloride), with a concentration of $\left.10^{-3} \mathrm{~mol} \mathrm{~L}^{-1}\right]$ necessary to reach the zero value of the streaming potential. All measurements were run at room temperature.

The thermogravimetric analysis (TGA) was performed on a STA 449 F1 Jupiter device (Netzsch, Germany). Approximately $10 \mathrm{mg}$ of each sample were heated in an open alumina crucible, in nitrogen atmosphere, with a flow rate of $50 \mathrm{~mL} \mathrm{~min}^{-1}$ and a heating rate of $10^{\circ} \mathrm{C} \mathrm{min}{ }^{-1}$. Samples were heated in the $30-700^{\circ} \mathrm{C}$ temperature range.

\section{Results and discussions}

The ratio between the organic and inorganic parts in the $\mathrm{CaCO}_{3}$ based composites plays an important role in the inner structure of the materials, controlling the polymer network crosslinking density, the nature of the inorganic polymorphs or the ratio between polymorphs. Therefore, in this study the $\mathrm{CaCO}$ /polymer weight ratio was $50 / 1$, as obtained by changing either the initial concentration of the polyanion solutions ( 0.05 or 0.06 wt. $\%$ ) or molar ratio, $n^{+} / n^{-}$ ( 0.2 or 0.4$)$, or the inorganic precursors concentration $(0.25$ or $0.3 \mathrm{M})$. Similar samples, prepared with the same polymers but with different concentrations, were studied in a previous paper [19], and the main observation was 


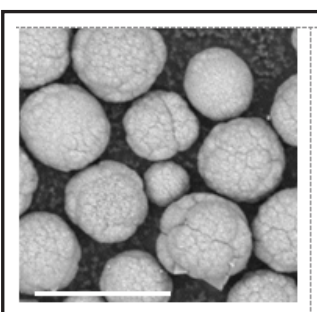

$\mathrm{C}_{0.25}$

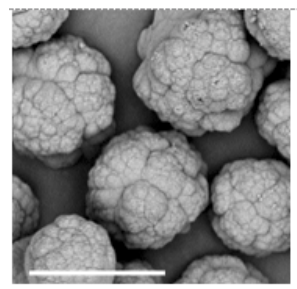

$\mathrm{C}_{0.3}$

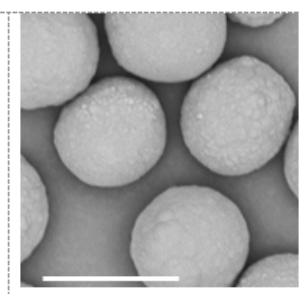

$\mathrm{C}_{0.25} / \mathrm{PSA}_{0.05}$

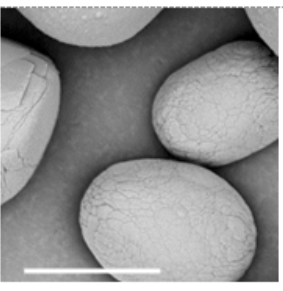

$\mathrm{C}_{0.3 / \mathrm{PSA}_{0.06}}$

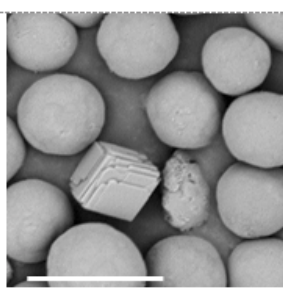

$\mathrm{C}_{0.25} / \mathrm{CSA}_{0.05}$

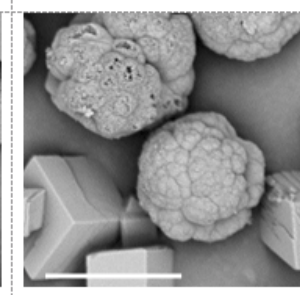

$\mathrm{C}_{0.3} / \mathrm{CSA}_{0.06}$
Fig.1. SEM images of $\mathrm{CaCO}_{3} /$ polyanion particles prepared with initial concentration of the polyanions solutions ( 0.05 or $0.06 \mathrm{wt} . \%)$ and the inorganic concentration ( 0.25 or $0.3 \mathrm{M})$; scale bar- $10 \mu \mathrm{m}$

that by increasing the inorganic concentration from $0.05 \mathrm{M}$ to $0.3 \mathrm{M}$ the particles sizes increased, irrespective of polyanion structure. In this study, the polymer concentration was decreased up to 0.05 and 0.06 wt.\%, closer to the total weight polymer concentration in the NPEC dispersions, aiming to obtain samples with a similar $\mathrm{CaCO}_{3} / \mathrm{polymer}$ w eight ratio.

Some SEM images of the polyanion based samples as well as samples prepared without polymer and the same inorganic concentration are shown in figure 1.

As shown in figure 1, the increase on the initial inorganic concentration increases the particles size, irrespective of polymer presence or its structure. Moreover, even if the PSA synthetic polymer has a more flexible backbone as compared to the semi-rigid one of CSA, the composite particles size looks similar for the same inorganic ratio. Usually, calcite crystallizes as rhombohedric particles, whereas vaterite particles exhibit a spherical shape. Therefore, taking into account the microparticles shape observed in the images included in figure 1 one may assume that PSA favours the formation of vaterite polymorph, whereas the presence of cubic and spherical

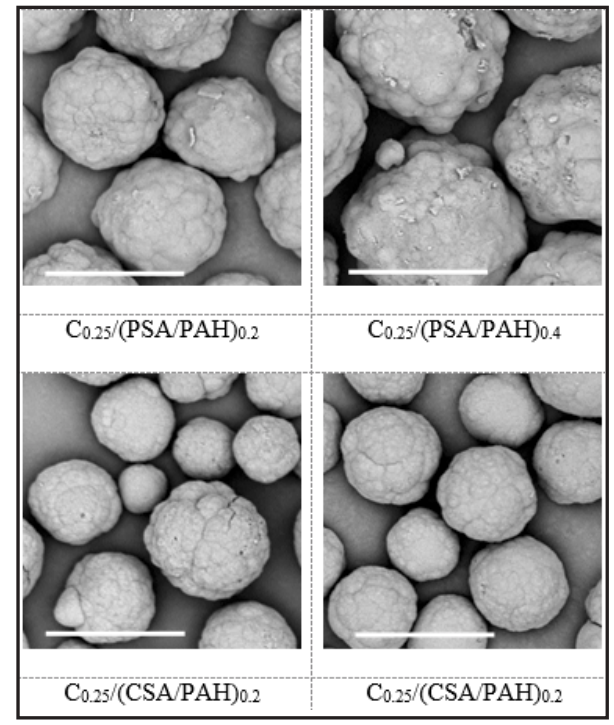

Fig. 2. SEM images of $\mathrm{CaCO}_{3} / \mathrm{NPEC}$ particles prepared with NPEC molar ratio of 0.2 or 0.4 , and the inorganic

concentrations of $0.25 \mathrm{M}$; scale bar - $10 \mu \mathrm{m}$

particles in CSA based composites suggests the formation of both calcite and vaterite polymorphs, irrespective of inorganic concentration.

The morphology of $\mathrm{CaCO}_{3} / \mathrm{NPEC}$ composite particles observed by SEM is shown in figure 2.

As shown in figure 2, particles surface morphology is similar for all NPEC based samples, irrespective of polyanion structure and NPEC molar ratio, and differs from that of the particles prepared with polyanion (figt. 1). These observations are in agreement with the results obtained when microparticles were prepared with NPEC based on the same polyanions and chitosan and the same ratio between the polymers [19]. How ever, larger particles were obtained when PSA was used in NPEC formation, most probably due to the higher flexibility of the free parts of the polyanion in excess that allows the formation of larger nets by crosslinking their ionic charges with calcium divalent ions.

Particles size distribution for each sample, determined by dynamic image analysis, are shown in figures 3 and 4 , the results on the mean and modal particles sizes being summarized in table 2.

\begin{tabular}{|l|c|c|c|}
\hline Sample code & Mean diam, $\mu \mathrm{m}$ & Mode diam, $\mu \mathrm{m}$ & Mean circularity \\
\hline $\mathrm{C}_{0.25}$ & 7.13 & 5.07 & 0.831 \\
\hline $\mathrm{C}_{0.25} / \mathrm{PSA}_{0.05}$ & 7.22 & 6.97 & 0.915 \\
\hline $\mathrm{C}_{0.25} / \mathrm{CSA}_{0.05}$ & 6.95 & 6.34 & 0.951 \\
\hline $\mathrm{C}_{0.3}$ & 8.69 & 6.07 & 0.849 \\
\hline $\mathrm{C}_{0.3} / \mathrm{PSA} 0.06$ & 11.38 & 10.89 & 0.885 \\
\hline $\mathrm{C}_{0.3} / \mathrm{CSA} 0.06$ & 10.14 & 9.68 & 0.859 \\
\hline $\mathrm{C}_{0.25} /(\mathrm{PSA} / \mathrm{PAH}) 0.2$ & 11.70 & 10.12 & 0.836 \\
\hline $\mathrm{C}_{0.25} /(\mathrm{PSA} / \mathrm{PAH}) 0.4$ & 11.92 & 9.43 & 0.815 \\
\hline $\mathrm{C}_{0.25} /(\mathrm{CSA} / \mathrm{PAH}) 0.2$ & 8.09 & 6.83 & 0.871 \\
\hline $\mathrm{C}_{0.25} /(\mathrm{CSA} / \mathrm{PAH}) 0.4$ & 8.45 & 7.43 & 0.881 \\
\hline
\end{tabular}

Table 2

MEAN AND MODE DIAMETER AND CIRCULARITY DETERMINED BY FPIA 


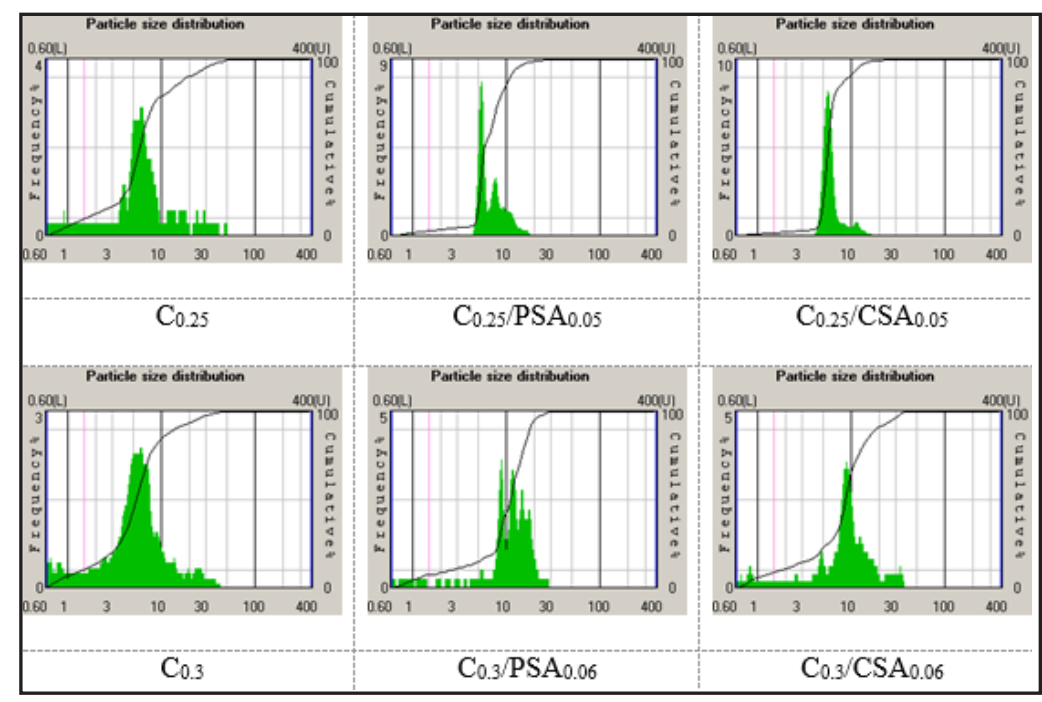

Fig. 3. Particles size distribution obtained by FPIA measurements of $\mathrm{CaCO}_{3} /$ polyanion microparticles

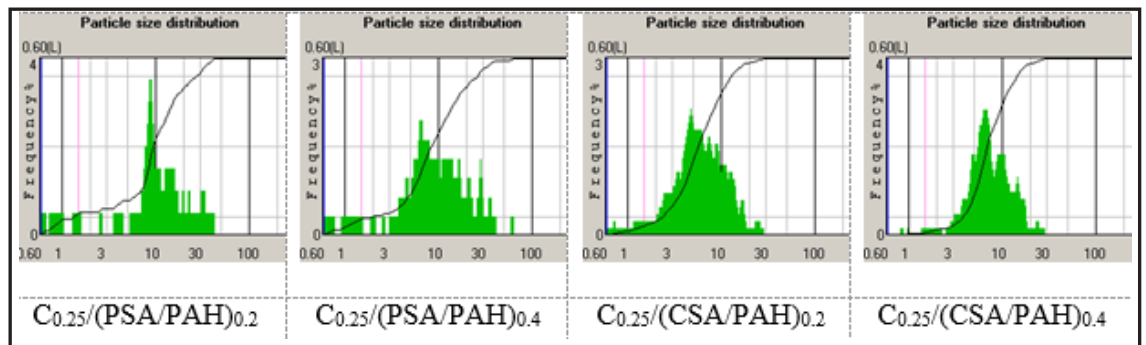

Fig. 4. Particles size distribution obtained by FPIA measurements of $\mathrm{CaCO}_{3} / \mathrm{NPEC}$ microparticles

Table 3

As shown in figure 3 , the particles size dispersity decreases when the polyanions were used in composites preparation, as compared to the samples prepared without polymer and the same inorganic concentration. This may be an evidence for a good control of the crystallization played by the polyanion templates. However, the particles size distribution looks wider when NPECs were used (fig. 4). To further sustain the particles size distribution, the values of mean and modal diameter included in table 2 can be considered. As shown by all graphs in figures 3 and 4 , non-symmetric distribution curves for the particles size were obtained for each investigated sample. Therefore, the mean and mode diameter have different values, as shown in table 2. Usually, mean diameter is a calculated value similar to the concept of average, whereas the mode diameter is the highest peak of the frequency distribution and represents the particle size (or size range) most commonly found in the distribution. Even if the mode diameter is not as commonly used, it can be descriptive and can be a further evidence of particles size distribution broadness: closer mean and mode values can be ascribed to a narrow size distribution. Therefore, as values in table 2 show, the closer values were obtained for samples prepared with both polyanions and the lowest inorganic concentration $(0.25 \mathrm{M})$. At the same time, the circularity values for that two samples are the closest to 1 (ascribed to the spheres) whereas for the other samples the values are lower than 0.9, suggesting the presence of rhombohedral or egg-shaped particles.

Since all the polymers involved in particles formation contain ionic groups, one should expect the overall particles charge density and surface zeta potential to be influenced by the amount of included polymer. Table 3 summarizes the complementary electrokinetic measurements carried out on the composites, namely the particles charge density (CD) and the zeta-potential values (ZP).

The $\mathrm{CaCO}_{3} /$ polymer ratio is almost constant in the composite particles ( 50/1, table 1$)$ but the initial precursors concentrations varied in sample preparation.

PARTICLES CHARGE DENSITY (CD) AND ZETA-POTENTIAL (ZP) OF $\mathrm{CACO}_{3}$ COMPOSITE PARTICLES

\begin{tabular}{|l|c|c|}
\hline Sample code & CD, meq/g & $\mathrm{ZP}, \mathrm{mV}$ \\
\hline $\mathrm{C}_{0.25}$ & -28.30 & -7.6 \\
\hline $\mathrm{C}_{0.25} / \mathrm{PSA}_{0.05}$ & -257.46 & -24.2 \\
\hline $\mathrm{C}_{0.25} / \mathrm{CSA}_{0.05}$ & -205.99 & -20.3 \\
\hline $\mathrm{C}_{0.3}$ & -41.47 & -9.7 \\
\hline $\mathrm{C}_{0.3} / \mathrm{PSA}_{0.06}$ & -294.76 & -26.8 \\
\hline $\mathrm{C}_{0.3} / \mathrm{CSA} 0.06$ & -239.52 & -23.1 \\
\hline $\mathrm{C}_{0.25} /(\mathrm{PSA} / \mathrm{PAH}) 0.2$ & -156.79 & -16.7 \\
\hline $\mathrm{C}_{0.25} /(\mathrm{PSA} \mathrm{PAH}) 0.4$ & -124.44 & -13.7 \\
\hline $\mathrm{C}_{0.25} /(\mathrm{CSA} / \mathrm{PAH}) 0.2$ & $-113,64$ & -13.6 \\
\hline $\mathrm{C}_{0.25} /(\mathrm{CSA} / \mathrm{PAH}) 0.4$ & -94.94 & -11.1 \\
\hline
\end{tabular}

Accordingly, increasing precursor's concentration in the initial mixture increased the CD and ZP values. However, the highest increase of both CD and ZP values has been obtained when polyanions were involved in composite preparation. At the same time, for the same initial concentrations higher values were obtained when PSA was used, which can be an evidence of the higher amount of this polymer included in the composites even if the same amount as CSA has been used in the initial mixtures. The differences should be understood taking into account the molar mass of the polyanions ( 279 and $463 \mathrm{~g} / \mathrm{mol}$ for PSA and CSA, respectively), for the same weight ( 0.05 or 0.06 wt. \%) the PSA aqueous solution containing a higher number of molecules and thus a higher solution charge density. Lower CD and ZP values were obtained for NPEC based composites, as compared to polyanion based composites. 
During NPECs nanoparticle formation, part of polyanion charges are compensated by polycation ones, and therefore the CD and ZP values of NPECs dispersions are lower than that of the corresponding polyanion solution. Moreover, the higher the $n^{+} / n^{-}$value, the higher content in polycation and thus the lower CD and ZP values are obtained. This trend is also observed in the NPEC based composites, higher values being obtained for the same molar ratio when PSA was used.

Even if $C D$ and ZP values can be indirectly ascribed to the polymer content in the NPECs based composites, the results are not relevant. In this case, the polyanion charges already compensated by the polycation cannot be determined by the above mentioned methods, but only the free polyanion charges in excess. Therefore, to avoid the method limits, thermogravimetric measurements were performed, comparing the weight loss at $500^{\circ} \mathrm{C}$ of composite microparticles to that of $\mathrm{CaCO}_{3}$ ones. Thus, to further demonstrate polymers presence into the composite, in figures 5 and 6 the TGA plots of $\mathrm{CaCO}_{3} /$ polymer composites with various contents in $\mathrm{CaCO}_{3}$ as compared to the TGA curves of $\mathrm{CaCO}_{3}$ are presented. Tables 4 and 5 summarize the thermogravimetric data for all investigated samples.

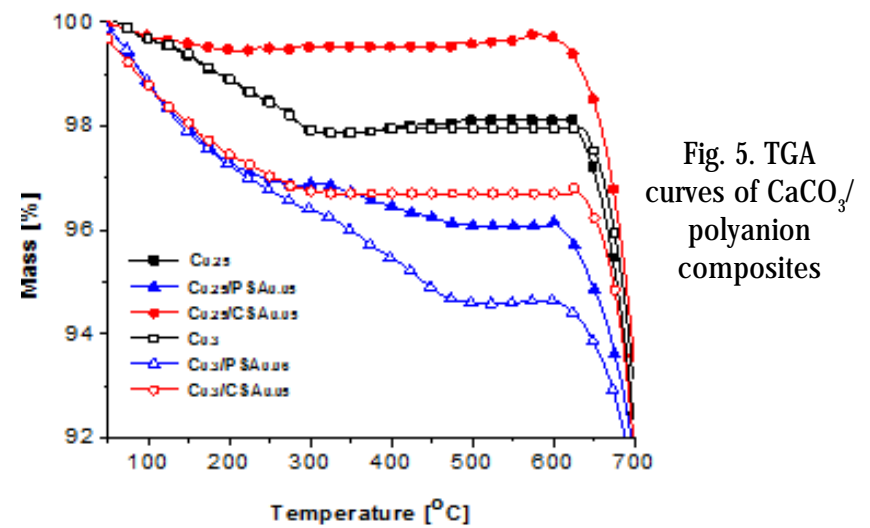

Samples $\mathrm{C}_{025}$ and $\mathrm{C}_{03}$ are thermally stable up to about $500^{\circ} \mathrm{C}$ (fig. 5), the $\sim 1.8 \%$ weight loss of both samples (table 4) being ascribed to the removal of intrinsic water content on the particles. The thermal decomposition recorded above $600^{\circ} \mathrm{C}$, with the highest mass losses, corresponds to material degradation to $\mathrm{CaO}[22,23]$. The increase of precursors concentration determines a slight decrease in intrinsic water content $1.78 \%$ and $1.84 \%$ for $\mathrm{C}_{0.25}$ and $\mathrm{C}_{0,3}$ respectively), also reflected in the mass residues differences recorded at $700^{\circ} \mathrm{C}(91.85 \%$ and 92.58 $\%)$.

The thermal behaviour of the polyanion-based composite samples depends on the structure of polymers. Thus, the thermal degradation of $\mathrm{CaCO}_{2} / \mathrm{PSA}$ composites takes place in three stages. During the first degradation step, in the temperature range $50-180^{\circ} \mathrm{C}$, the loss of adsorbed water molecules takes place simultaneously with the first polymer decomposition step with transformation of vicinal carboxylic groups on the backbone to anhydride structures and the degradation of sulfonic groups with elimination of SO [24]. The second decomposition region, between 325 and $475^{\circ} \mathrm{C}$ (table 4), is the main polymeric decomposition step, when fragmentation of anhydride rings and depolymerisation reactions take place. Taking into account that the third decomposition step, above $600^{\circ} \mathrm{C}$, corresponds to $\mathrm{CaCO}_{3}$ degradation, the polymer content can be ascribed to the mass loss at $550^{\circ} \mathrm{C}$ as compared to samples prepared with the same inorganic concentration but without polymer. Thus, even if the ratio $\mathrm{CaCO}_{3} / \mathrm{PSA}$ is constant, an increase of polymer concentration in the crystallization system leads to an increase of polymer content in the composite microparticles.

The semi-rigid structure of CSA determines a slightly improved thermal stability of the corresponding composites (table 4), as compared to microparticles based on PSA, with a more flexible backbone. Actually, CSA does not decompose below $600^{\circ} \mathrm{C}$, the mass loss at $550^{\circ} \mathrm{C}$ being

\begin{tabular}{|l|c|c|c|c|c|c|c|}
\hline & & $\left.{ }^{\circ} \mathrm{C}\right)$ & $\left.{ }^{\circ} \mathrm{C}\right)$ & $\left.{ }^{\circ} \mathrm{C}\right)$ & $(\%)$ & $(\%)$ & $(\%)$ \\
\hline $\mathrm{C}_{0.25}$ & I & 40 & 77,$188 ; 281$ & 293 & 1.69 & 1.78 & 92.58 \\
& II & 613 & 643 & 697 & 5.50 & & \\
\hline \multirow{3}{*}{$\mathrm{C}_{0.25} / \mathrm{PSA}_{0.05}$} & I & 68 & 80 & 188 & 3.15 & 3.91 & 91.29 \\
& II & 326 & 367 & 475 & 0.70 & & \\
& III & 602 & 643 & 695 & 4.78 & & \\
\hline \multirow{2}{*}{$\mathrm{C}_{0.25} / \mathrm{CSA}_{0.03}$} & I & 73 & 82 & 100 & 0.40 & 0.41 & 92.98 \\
& II & 605 & 628 & 694 & 6.60 & & \\
\hline $\mathrm{C}_{0.3}$ & I & 68 & $75 ; 167,217 ; 281$ & 290 & 1.58 & 1.84 & 91.85 \\
& II & 596 & 630 & 694 & 6.23 & & \\
\hline \multirow{3}{*}{$\mathrm{C}_{0.3} / \mathrm{PSA}_{0.06}$} & I & 54 & 79 & 133 & 3.52 & 5.40 & 90.81 \\
& II & 325 & 437 & 465 & 1.79 & & \\
& III & 603 & 643 & 695 & 3.71 & & \\
\hline \multirow{2}{*}{$\mathrm{C}_{0.3} / \mathrm{CSA}_{0.06}$} & I & 51 & 74 & 233 & 2.98 & 3.03 & 91.86 \\
& II & 626 & 650 & 689 & 5.04 & & \\
\hline
\end{tabular}

Table 4

THERMOGRAVIMETRIC DATA OF $\mathrm{CACO}_{3} /$ POLYANION COMPOSITES

$T_{i}$ - onset thermal degradation temperature; $T_{\max }$ - temperature that corresponds to the maximum rate of decomposition for each stage evaluated from the peaks of the DTG curves; $T_{f}$ - endset thermal degradation temperature; $W_{m}-$ mass loss; $W_{m 50}-$ mass loss at $550^{\circ} C$; $W_{\text {rez 550 }}$ - percentage of residue remained at $700{ }^{\circ} \mathrm{C}$. 


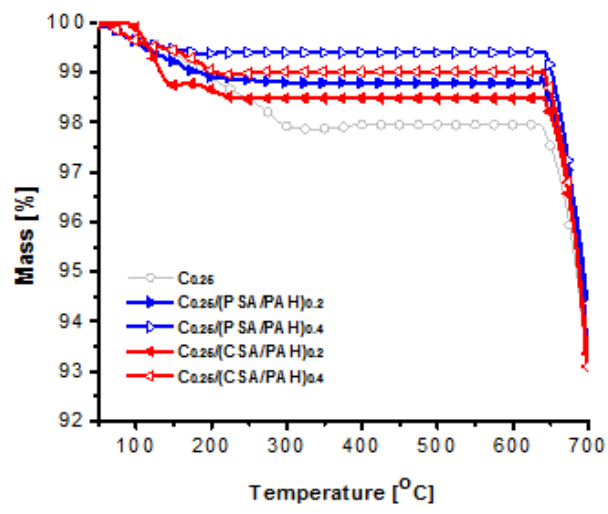

Fig. 6. TGA curves of $\mathrm{CaCO}_{3} / \mathrm{NPEC}$ composites

\begin{tabular}{|c|c|c|c|c|c|c|c|}
\hline Sample & Stage & $\begin{array}{c}\mathrm{T}_{\mathrm{i}} \\
\left({ }^{\circ} \mathrm{C}\right)\end{array}$ & $\begin{array}{l}\mathrm{T}_{\max } \\
\left({ }^{\circ} \mathrm{C}\right)\end{array}$ & $\begin{array}{l}\mathrm{T}_{\mathrm{f}} \\
\left({ }^{\circ} \mathrm{C}\right)\end{array}$ & $\begin{array}{l}W_{\mathrm{m}} \\
(\%)\end{array}$ & $\begin{array}{c}W_{m 550} \\
(\%)\end{array}$ & $\begin{array}{c}\mathrm{W}_{\text {rex } 700} \\
(\%)\end{array}$ \\
\hline $\mathrm{C}_{0.25} /(\mathrm{PSA} / \mathrm{PAH})_{0.2}$ & $\begin{array}{l}\text { I } \\
\text { II } \\
\text { III }\end{array}$ & $\begin{array}{c}95 \\
186 \\
603\end{array}$ & $\begin{array}{l}116 \\
189 \\
644\end{array}$ & $\begin{array}{l}140 \\
232 \\
692\end{array}$ & $\begin{array}{l}1.18 \\
0.30 \\
5.44\end{array}$ & 1.82 & 92.08 \\
\hline $\mathrm{C}_{0.25} /(\mathrm{PSA} / \mathrm{PAH})_{0.4}$ & $\begin{array}{l}\text { I } \\
\text { II } \\
\text { III }\end{array}$ & $\begin{array}{c}67 \\
160 \\
600\end{array}$ & $\begin{array}{c}82 \\
190 \\
643\end{array}$ & $\begin{array}{r}111 \\
208 \\
692\end{array}$ & $\begin{array}{l}0.47 \\
0.46 \\
6.32\end{array}$ & 1.05 & 92.58 \\
\hline $\mathrm{C}_{0.25} /(\mathrm{CSA} / \mathrm{PAH})_{0.2}$ & $\begin{array}{l}\text { I } \\
\text { II }\end{array}$ & $\begin{array}{l}54 \\
608\end{array}$ & $\begin{array}{l}79 \\
673\end{array}$ & $\begin{array}{l}177 \\
689\end{array}$ & $\begin{array}{l}1.12 \\
4.70\end{array}$ & 1.15 & 93.91 \\
\hline $\mathrm{C}_{0.25} /(\mathrm{CSA} / \mathrm{PAH}) 0.4$ & $\begin{array}{l}\text { I } \\
\text { II }\end{array}$ & $\begin{array}{l}64 \\
600\end{array}$ & $\begin{array}{l}77 \\
644\end{array}$ & $\begin{array}{l}106 \\
691\end{array}$ & $\begin{array}{l}0.38 \\
6.51\end{array}$ & 0.45 & 93.03 \\
\hline
\end{tabular}

$T_{i}$ - onset thermal degradation temperature; $T_{\max }$ - temperature that corresponds to the maximum rate of decomposition for each stage evaluated from the peaks of the DTG curves; $T_{f}$ - endset thermal degradation temperature; $W_{m}$ - mass loss; $W_{m 550}$ - mass loss at $550^{\circ} \mathrm{C} ; W_{\text {rez } 550}$ - percentage of residue remained at $700^{\circ} \mathrm{C}$

ascribed only to the removal of adsorbed and/or combined water molecules from inorganic/organic phases.

Usually, the formation of NPECs improves the thermal stability as compared to that of the corresponding polyelectrolytes [25].

Therefore, as shown in figure 6 , the thermal stability of composites based on NPEC increased as compared with composites prepared with the corresponding polyanions, their stability being higher than that of $\mathrm{C}_{0.25}$. Increasing the polycation content, meaning increasing the intrinsic polyanion/polycation charge compensation, increases composites thermal stability, irrespective of polyanion structure, the NPECs thermal decomposition taking place above $600^{\circ} \mathrm{C}$, in parallel with $\mathrm{CaCO}_{3}$ degradation to $\mathrm{CaO}$.

\section{Conclusions}

This study focussed on the synthesis, characterization and thermal stability of some $\mathrm{CaCO}_{3}$ /polymer composites obtained by crystal growth from supersaturated solutions and controlled by polymer structure (PSA - a synthetic, flexible polymer, and CSA - a sulfated glycosaminoglycan with a semi-rigid macromolecular chain) or by using NPECS (with the same polyanions and $\mathrm{PAH}$ ). The $\mathrm{CaCO}_{3} /$ polymer weight ratio was kept constant at 50/1, varying the initial concentration of the polyanions solutions $(0.05$ or 0.06 wt.\%), the molar ratio of NPECs, $n+/ n-(0.2$ or 0.4$)$, or the inorganic precursors concentrations $(0.25$ or $0.3 \mathrm{M})$. The thermal behaviour of the polyanion-based composite samples depends on the structure of polymers. The semi- rigid structure of CSA determines a slightly improved thermal stability of the corresponding composites, which do not decompose below $600^{\circ} \mathrm{C}$, the mass loss up to $550^{\circ} \mathrm{C}$ being ascribed only to the removal of adsorbed and/or combined water molecules from inorganic/organic phases. The composites prepared with NPECs showed the highest thermal stability, irrespective of the polyanion used in their preparation and irrespective of molar ratio between charges.

Acknowledgements: This work was supported by a grant of the Romanian National Authority for Scientific Research and Innovation, CNCS -UEFISCDI, project number PN-II-RU-TE-2014-4-1433.

\section{References}

1.NEKHAMANURAK, B., PATANATHABUTR, P., HONGSRIPHAN, N., Energy Procedia, 56, 2014, p. 118

2. JIPA, S., ZAHARESCU, T., SUPAPHOL, P., Polym. Bull., 64, 2010, p. 783 3. HOSODA, N., SUGAWARA, A., KATO, T., Macromolecules, 36, 2003, p. 6449

4. SHEN, Q., CHEN, Y., WEI, H., ZHAO, Y., WANG, D., XU, D., Cryst. Growth Des., 5, 2005, p. 1387

5. SU, Y.L., YANG, H.R, SHI, W.X., GUO, H.X., ZHAO, Y., WANG, D.J., Colloid Surf A, 355, 2010, p. 158

6. AZIZ, B., GEBAUER, D., HEDIN, N., Cryst. Eng. Comm., 13, 2011, p. 4641

7. LEE, Y., MIN HAHM, Y., MATSUYA, S., NAKAGAWA, M., ISHIKAWA, K., J. Mater. Sci., 42, 2007, p. 5728-5735 
8. ZHAO, Y.Y., LI, S.X., YU, L., LIU, Y.H., WANG, X.Q., JIAO, J.J., J. Cryst. Growth, 324, 2011, p. 278

9. DLUGOSZ, M., BULWAN, M., KANIA, G., NOWAKOWSKA, M., ZAPOTOCZNY, S., J. Nanopart. Res., 14, 2012, p. 1313

10. MANOLI, F., DALAS, E., J. Mater. Sci. Mater. Med., 13, 2002, p. 155 11. YU, J., LEI, M., CHENG, B., ZHAO, X., J. Solid State Chem., 177, 2004, p. 681

12. MIHAI, M, BUCATARIU, .F, AFLORI, M., SCHWARZ, S., J. Cryst. Growth, 351, 2012, p. 23

13. MIHAI, M., MOUNTRICHAS, G., PISPAS, S., STOICA, I., AFLORI, M., AUF DER LANDWEHR, M., NEDA, I., SCHWARZ, S., J. Appl. Cryst., 46, 2013, p. 1455

14. MIHAI, M., BUNIA, I., DOROFTEI, F., VARGANICI, C.D., SIMIONESCU, B.C. Chem. Eur. J., 21, 2015, p. 5220

15. ORME, C.A., NOY, A.,WIERZBICKI, A., MCBRIDE, M.T., GRANTHAM, M., TENG, H.H., DOVE, P.M., DEYOREO, J.J ., Nature, 411, 2001, p. 775 16. WEINER, S., SAGI, I., ADDADI, L., Science, 309, 2005, p. 1027
17. MELDRUM, F.C., Int. Mater. Rev. 48, 2003, p. 187

18. ZHAO, Y., CHEN, Z.H., WANG, H.Y., WANG, J.J., Cryst. Growth Des., 9, 2009, p. 4984

19. MIHAI, M., SCHWARZ, S., SIMON, F., Cryst. Growth Des., 13, 2013, p. 3144

20. MIHAI, M., SCHWARZ, S., DOROFTEI, F., SIMIONESCU, B.C., Cryst. Growth Des., 14, 2014, p. 6073

21. ILIOPOULOS, I., AUDERBERT, R., Macromolecules, 24, 1991, p. 2566

22. POPESCU, M.A., IOSIPESCU, R., MATEI, C., FAGARASAN, G., PLESU, V., Adv. Powder Technol., 25, 2014, p. 500

23. KOGA, N., YAMANE, Y., J. Therm. Anal. Calorim., 94, 2008, p. 379 24. AGGOUR, Y.A., Polym. Degrad. Stab., 60, 1998, p. 317

25. DRAGAN, S., DRANCA, I., GHIMICI, L., CRISTEA, M., FUNDUIANU, G., LUPASCU, T., Eur. Polym. J., 34, 1998, p. 733

Manuscript received: 6.09 .2017 